\title{
Uma análise tipológica preliminar do sistema de classificadores em línguas Arawák
}

\author{
A preliminary typological analysis of the system classifiers in Arawak languages
}

Camille Cardoso MIRANDA*

\begin{abstract}
RESUMO: O presente artigo objetiva descrever preliminarmente o sistema de classificadores em 15 línguas que compõem a família linguística Arawák (Arawák): Achaguá, Ashéninka Perené, Baniwa de Içana, Baure, Garifuna, Mehináku, Nanti, Palikur, Paresi, Resígaro, Tariana, Wapixana, Warekena, Waujá e Yawalapiti. Os classificadores são geralmente definidos como morfemas que ocorrem em estruturas da superfície que denotam algumas características semânticas associadas aos seus referentes. Os tipos de classificadores descritos neste estudo são os numerais, nominais, genitivos, verbais, locativos e com adjetivos. Como resultado, verificamos que os classificadores de número é o tipo mais comum entre essas línguas, enquanto o locativo e os adjetivos são os mais raros. Desse modo, estabelecemos um estudo tipológico preliminar para verificar os possíveis padrões do sistema de classificadores das 15 línguas que compõem a família Arawák.
\end{abstract}

PALAVRAS-CHAVE: Sistema de classificadores. Línguas Arawák. Tipologia Morfológica.

\begin{abstract}
This paper aims to describe, preliminarily, the system of classifiers in 15 languages that belongs the Arawak linguistic family: Achagua, Asheninka Perene, Baniwa de Içana, Baure, Garifuna, Mehinaku, Nanti, Palikur, Paresi, Resigaro, Tariana, Wapixana, Warekena, Wauja and Yawalapiti. Classifiers are generally defined as morphemes occurring in surface structures that denote some semantic feature associated with their referents. The types of classifiers described in this study are numerals, nominal, genitive, verbal, locative and adjectives. We verify that the number classifiers are the most common type among these languages, while the locative and adjectives are the rarest. We have thus established a preliminary typological study to verify the possible patterns of the classifier system of the 15 languages that make up the Arawak family.
\end{abstract}

KEYWORDS: System of classifiers. Arawak Languages. Morphological Typology.

\footnotetext{
* Doutoranda em Linguística pelo Instituto de Estudos da Linguagem (IEL), UNICAMP. Bolsista de Doutorado FAPESP (2018/18072-1). ORCID: .camiranda126@gmail.com
} 


\section{Introdução}

Todas as línguas do mundo apresentam classificação nominal ou sistemas de categorização, seja no que tange a questão de gênero gramatical (masculino, feminino, neutro), número (singular ou plural), termos de classe ou classificadores, este sendo presente em muitas línguas do continente africano, na América, na Ásia e na Oceania. Segundo Allan (1977, p. 285), existem notáveis semelhanças do sistema de classificadores em muitas línguas não relacionadas geneticamente e separadas geograficamente, exibindo um padrão tipológico bastante presente nas línguas do mundo.

De acordo com Senft, os estudos que remetem a um sistema de classificação nominal exibem vários tipos, como por exemplo, classificação de nomes, classificadores numerais, classificadores de verbos e sistema de gênero. Essas classificações são definidas e diferenciadas umas das outras. Para o autor, a discussão sobre classificação nominal deixou um número aberto de importantes questões. $\mathrm{Na}$ literatura sobre os sistemas de classificação nominal, é perceptível uma categorização baseada em critérios morfossintáticos, mas também semânticos. Os estudos dos sistemas de classificação nominal revelam uma série de funções funcionais (comunicativas) dos falantes. As línguas Arawák selecionadas para este estudo apresentam sistema de classificação nominal, um deles é o de classificadores, tópico a ser discutido neste trabalho.

Os classificadores são geralmente definidos como morfemas que ocorrem em estruturas da superfície, em condições específicas que denotam algumas características semânticas associadas aos seus referentes (AIKHENVALD, 2000a). Partindo de uma análise morfossintática da tipologia de classificadores observamos que existem diferentes tipos desse sistema, sendo os mais recorrentes: classificadores de números, nominais, classificadores genitivos utilizados em construções possessivas, classificadores de verbos, e outros mais raros como os classificadores 
locativos, adjetivos e dêiticos. Existe também a função anafórica que um classificador pode desempenhar em uma língua além de ser um morfema derivacional.

Diante disso, objetiva-se realizar um estudo preliminar do sistema de classificadores em 15 línguas que compõem a família Arawák: Achaguá, Ashéninka Perené, Baniwa de Içana, Baure, Garifuna, Mehináku, Nanti, Palikur, Paresi, Resígaro, Tariana, Wapixana, Warekena, Waujá e Yawalapiti. Como resultado, observamos que estas apresentam diferentes padrões em relação a tal fenômeno, sendo o mais comum o sistema de classificador de números e os mais raros: locativo e adjetivos. Desse modo, estabelecemos um estudo tipológico para verificar os possíveis padrões do sistema de classificadores nas línguas selecionadas.

\section{Línguas Arawák e informações gerais das línguas de análise}

A família Arawák contém um número amplo de línguas faladas na América do Sul. Aikhenvald (1999, p. 65) afirma que, geograficamente, as línguas Arawák expandiram-se para quatro países da América Central - Belize, Honduras, Guiana, Nicarágua e em oito países da América do Sul - Bolívia, Guiana Francesa, Suriname, Venezuela, Colômbia, Peru, Brasil, Argentina e Paraguai ${ }^{1}$. Conforme a autora, as línguas Arawák desempenharam um importante papel desde a chegada dos Europeus ao continente Americano, pois os primeiros povos nativos na América encontrados por Colombo falavam uma língua Arawák chamada Taino, que logo depois do contato tornou-se extinta, assim como Taino, outras línguas dessa família foram desparecendo. Atualmente, são aproximadamente 40 línguas que permanecem vivas.

É perceptível que, desde o contato com os europeus, as línguas ameríndias estão desaparecendo rapidamente, seja por conta dos números reduzidos de falantes ou pela falta de transmissão às gerações mais novas que acabam optando pelo o uso de línguas

\footnotetext{
${ }^{1}$ Atualmente na Argentina e Paraguai as línguas Arawák não são mais faladas.
} 
europeias (ex. Português e Espanhol) ou francas (ex. Língua Geral Amazônica ou Tucano). De acordo com as informações de Aikhenvald (1999), as línguas Arawák que foram faladas na costa norte da América do Sul deixaram de existir antes de 1700 . O desaparecimento de outras línguas dessa família também ocorreu nos afluentes do Rio Negro na Amazônia.

Desse modo, todas as línguas Arawák atualmente estão ameaçadas. Rebeliões indígenas frequentemente provocavam fortes migrações que algumas vezes terminavam na criação de um novo dialeto ou até mesmo de uma nova língua (cf. AIKHENVALD, 1999, p. 72). Aikhenvald mostra como exemplo o que ocorreu entre índios e escravos negros que falavam uma língua Arawák denominada Caribe Insular (Island Carib). Esse contato resultou na criação de um novo dialeto do Caribe Insular conhecido como Caribe Insular da América Central, Kariff, Black Carib ou Garifuna que deu origem a uma língua autônoma que atualmente é uma das línguas Arawák com maior número de falantes (cf. AIKHENVALD, 1999, p. 72).

No entanto muitas línguas Arawák estão apresentando mudanças em seus perfis, devido a influência gradativa de uma língua majoritária ou uma língua franca. As línguas Arawák faladas no Alto Rio Negro (Baré, Baniwa de Içana ou Warekena) estão sendo substituídas pela Língua Geral Amazônica (LGA), a língua Tucano na região da bacia do Vaupés também está influenciando fortemente a língua Tariana. $\mathrm{O}$ mesmo efeito parece ocorrer com a língua Yawalapiti. Na época da expedição dos irmãos Villas-Boas, houve o incentivo de casamento interétnico para evitar a extinção do povo, assim, muitos Yawalapiti acabavam utilizando a língua Kamayurá (língua Tupi-guarani que se tornou uma língua franca e o mesmo ocorreu com os Kamayurá, Kuikuro, Mehináku e Waujá). Os processos de mudanças linguísticas, os contatos e o número reduzido de falantes consequentemente podem prejudicar o conhecimento científico dessas línguas e a perda de alguns fenômenos linguísticos. 
No que diz respeito aos materiais produzidos sobre as línguas dessa família, a maioria deles foi coletado durante a segunda metade do século XX e descritos por linguistas do Summer Institute of Linguistics (SIL). Seguindo as informações de Aikhenvald (1999, p. 73), nenhuma língua Arawák com a possível exceção de Lokono e Resígaro foi fornecida uma gramática compreensível (fonologia, morfologia e sintaxe), dicionários ou coletânea de textos.

Aikhenvald (1999, p. 73) afirma que a unidade genética das línguas Arawák foi reconhecida pela primeira vez pelo missionário Italiano Salvadore Filippo Gilij (1783). O reconhecimento da família foi baseado a partir de uma comparação de Maipure, do Vale do Orinoco e Moxo da Bolívia. Gilij denominou a família Arawák como Maipure, mas Brinton (1891) e Karl von den Steinen (1894) a denominaram como seu nome atual Arawák (Aruák). Esse nome vem a partir de uma língua conhecida como Lokono Arawák ou Lokono Dian, ainda falada na Guiana Francesa, Suriname e Venezuela (cf. AIKHENVALD, 2012, p. 33).

Os estudos comparativos iniciados por Gilij (1783) foram continuados por von den Steinen que propôs a primeira subdivisão das línguas Arawák. Ele distingue NuArawák de Ta-Arawák, baseando-se na forma do prefixo pronominal de primeira pessoa. Aikhenvald (1999, p. 73) explica que embora não exista dúvida da afiliação genética das línguas Arawák, problemas ainda podem ser encontrados no que diz respeito à relação genética entre a família e possíveis relações genéticas com outros grupos. Payne (1991, p. 363) afirma que a maioria dos estudiosos tendem a denominar "Maipuran" (ou o menos comum "Maipurean" como em SUAREZ, 1974; KAUFMAN) para se referir ao grupo principal de línguas inquestionavelmente relacionadas. Já o termo Arawák ou Aruák denota um tronco linguístico ou filo que potencialmente relaciona essas línguas Maipuran a outras línguas mais distantes dessa família.

Em relação às propriedades gramaticais das línguas da família Arawák, Aikhenvald (1999) explica que elas são facilmente reconhecidas por compartilharem 
alguns aspectos gramaticais em comuns, tais como o prefixo nominal $\{$ nu- $\}$ ou $\{$-ta $\}$ que designa primeira pessoa no singular, o morfema $\{\mathrm{pi}-\}$ que se refere à segunda pessoa do singular/plural, o prefixo $\{\mathrm{ka}-\}$ que codifica oração relativa ou atributiva como "ter" etc. No que diz respeito aos estudos de tipologia morfológica, a autora explica que as línguas desta família apresentam propriedades de línguas aglutinantes e polissintéticas.

Das 40 línguas que compõem a família Arawák, selecionamos 15 para analisar e discutir o sistema de classificadores. Os materiais utilizados partem da compilação de estudos que tratam de aspectos referentes à morfossintaxe e que possibilitou a verificação dos padrões de classificadores ou classificação nominal encontrados nessas línguas.

Assim sendo, para a língua Achaguá utilizamos o trabalho de Wilson e Levinsohn (1992) que aborda diferentes aspectos gramaticais da língua e um deles é os classificadores. A língua Achaguá é falada na Amazônia Colombiana e Venezuela e está em perigo de extinção. É uma língua agrupada no grupo Norte-Arawák e faz parte do ramo da Amazônia Colombiana. Já a língua Ashéninka Perené falada atualmente na Amazônia Peruana faz parte do grupo Sul-Arawák, a língua é inserida no ramo Campa. O trabalho utilizado para verificar o sistema de classificador é de Mihas (2010) que trata especificamente desse sistema na língua. Para a língua Baniwa de Içana, utilizamos os estudos de Aikhenvald $(1994,2007)$ que trata especificamente do sistema de classificadores. A língua é falada na fronteira entre o Brasil, a Colômbia e a Venezuela. É agrupada por Aikhenvald (1999) no ramo da Bacia do Rio Negro juntamente com Tariana e Warekena, fazendo parte do grupo Norte-Arawák.

A língua Baure é falada no noroeste da Bolívia, na parte Amazônia boliviana, agrupada no grupo Sul-Arawák. O trabalho utilizado para analisar o sistema de classificadores nessa língua foi a tese de doutorado de Danielsen (2007) que esboça algumas considerações sobre esse fenômeno. Para a língua Garifuna, utilizamos a tese 
de Larsen-Haurholm (2016) que esboça algumas considerações sobre o sistema de classificadores relacionais (posse) nessa língua. A língua é falada em Honduras, Guatemala e Belize (América Central), fazendo parte do ramo Caribe ou extremo Norte, inserida por Aikhenvald no grupo Norte-Arawák.

A língua Nanti é falada na Amazônia Peruana, ela está dentro do ramo Campa, fazendo parte do Grupo Sul-Arawák. Para verificar o sistema de classificadores em Nant,i utilizamos o trabalho de Michael (2006) que trata especificamente desse fenômeno. Utilizamos o trabalho de Aikhenvald e Green (1998) para verificar o sistema de classificação nominal em Palikur. As autoras trazem subsídios essenciais para compreender o sistema de classificadores. A língua é inserida no grupo do NorteArawák, no ramo Palikur (cf. AIKHENVALD, 1999). Os trabalhos de Brandão (2015, 2016) foram utilizados para verificar o sistema de classificadores na língua Paresi. A língua é inserida no ramo Paresi-Xingu, fazendo parte do grupo das línguas do SulArawák.

As línguas Mehináku, Waujá e Yawalapiti são faladas no Alto Rio Xingu, são inseridas juntamente com Paresi, no ramo Paresi-Xingu, fazendo parte do grupo das línguas do Sul-Arawák. Para a língua Mehináku, utilizamos os trabalhos de Corbera Mori (2007, 2012) que trata especificamente das estruturas lexicais/nominais dessa língua inserindo, portanto, os classificadores. Para a língua Yawalapiti, usamos a dissertação de Mijuca (1992) que trata dos aspectos fonológicos e morfológicos, o trabalho traz algumas considerações de classificadores o que auxiliou na análise. Utilizamos a tese de Postigo (2014) para verificar o sistema de classificadores em Waujá. A língua Resígaro falada na Amazônia Peruana, que está em grande risco de extinção, é classificada por Aikhenvald no ramo das línguas Arawák Colombianas, no grupo Norte-Arawák. Para essa língua utilizamos o estudo de Allin (1976) para verificar o sistema de classificadores. 
Utilizamos os trabalhos de Aikhenvald $(1994,2000 \mathrm{~b})$ para analisar o sistema de classificadores em Tariana. A língua Tariana é falada na região do Vaupés no Alto Rio Negro (Estado do Amazonas), ela faz parte do grupo Norte-Arawák, no ramo Alto Rio Negro, juntamente com Baniwa de Içana e Warekena (Guarequena), esta, também falada no Alto Rio Negro, apresenta o sistema de classificadores numerais. A análise desse fenômeno foi realizada a partir do trabalho de Aikhenvald (1998). E por fim, a língua Wapixana que é falada no estado de Roraima, entre o rio Branco e o Rupunumi. O trabalho utilizado para analisar o sistema de classificadores foi a tese de Santos (2006) que trata dos aspectos morfossintáticos dessa língua. Como podemos observar, as línguas Arawák são reunidas em dois grandes grupos: Sul-Arawák e NorteArawák. O quadro 1 abaixo (adaptado) exibe o agrupamento das línguas selecionadas para este trabalho de acordo com Aikhenvald (1999, p. 67).

Quadro 1 - Agrupamento das línguas Arawák analisadas.

\begin{tabular}{|l|l|}
\hline Línguas Arawák do Norte & Línguas Arawák do Norte Sul \\
\hline Achaguá & Ashéninka Perené \\
\hline Baniwa de Içana & Baure \\
\hline Guarifuna & Mehináku \\
\hline Palikur & Nanti (Campa) \\
\hline Resígaro & Paresi \\
\hline Tariana & Waujá \\
\hline Warekena & Yawalapiti \\
\hline Wapixana & \\
\hline
\end{tabular}

Fonte: adaptado de Aikhenvald (1999, p. 66-69).

\section{Sistema de classificação nominal: Classificadores}

Antes de começarmos a discutir sobre a morfossintaxe dos classificadores, é interessante mencionar alguns pontos importantes de sistema de classificação nominal. Aikhenvald (2000a) assume que quase todas as línguas têm algum significado gramatical para categorização linguística dos nomes. Grinevald (2000, p. 
55) insere os classificadores em um ponto intermediário de um sistema continuum léxicogramatical. De acordo com a autora, o termo "Lexical" parte do léxico e sua dinâmica de construção de palavras que é semanticamente composicional, enquanto "Gramatical" significa parte da morfossintaxe de uma língua (cf. GRINEVALD, 2000, p. 55). Grinevald (2000) considera dois tipos de sistemas lexicais. O primeiro faz parte de um nível gramatical que foi denominado por "Grammatical end of the continuum" que inclui o sistema de gênero e o sistema de classe nominal, enquanto o segundo está dentro do nível lexical "Lexical end of the Continuum", inserindo os termos de medidas e termos de classe.

Em muitas literaturas, o sistema de gênero e de classe nominal foram tratados como um mesmo fenômeno (cf. CORBETT, 1991; AIKHENVALD 2000a). Corbett (1991) afirma que uma língua pode ter duas ou mais classes nominais ou gêneros. Para o autor, a palavra gênero é usada não apenas para um grupo de nomes, mas também para toda uma categoria. Desse modo, podemos afirmar que uma língua particular pode ter três tipos de gêneros: masculino, feminino e neutro. Aikhenvald (2000a) afirma que as classes dos nomes e de gênero são sistemas de concordância gramaticalizados que se correlacionam com algumas características semânticas do referente, por isso que às vezes são chamados de classe de concordância. A autora afirma que o termo gênero foi utilizado pela primeira vez pelo filósofo Protágoras para dividir os nomes do grego em três classes: feminino, masculino e inanimado (neutro). Esse sistema é bastante comum em línguas europeias.

Diferentemente de Corbett (1991) e Aikhenvald (2000a) que tratam os sistemas de gênero e classe nominal juntos, Grinevald (2000) discute os dois separadamente. A autora assume que a característica principal de um sistema de gênero é que este é um tipo de classificação nominal que nem sempre é evidente no próprio nome, mas pode ser codificado em outros elementos da sentença (artigos, pronomes) que variam de língua para língua. Grinevald explica que o sistema de gênero pode ter uma ordem 
decrescente de probabilidade, tal como, dentro de um sintagma nominal, adjetivo, demonstrativo, artigo, numerais, em construções de posse, dentro de uma forma pronominal independente, como pronomes pessoais, relativos ou em questões interrogativas com $W H-(Q u-)$. Os gêneros podem também ser presentes em orações predicativas como elementos que marcam a concordância dos argumentos do núcleo. Em outros lugares dentro da sentença, raramente eles ocorrem com advérbios, adposições ou complementizadores (cf. GRINEVALD, 2000).

Conforme Aikhenvald (1999, p. 83), a maioria das línguas Arawák tem dois gêneros (masculino vs feminino) como afixos de trans-referência e algumas possuem gênero neutro. Como um sistema de classificação nominal, o sistema de gênero são geralmente morfemas portmanteau combinando informações sobre classe nominal com número, pessoa, caso, etc. Grinevald (2000) assume que o gênero é atribuído para todos os nomes de uma determinada língua e é obrigatoriamente marcado. Esse sistema é limitado na classificação nominal em termos de número em sua classe. Quando as línguas africanas começaram a ser estudadas, elas chamaram atenção por conta de um sistema de gênero bastante amplo, a partir dos estudos dessas línguas, alguns autores denominaram esse sistema de classe nominal/nomes.

O sistema de classe nominal, assim como de gênero, é tratado como um dos principais sistemas de classificação nominal. Os dois sistemas são contrastivos com o sistema de classificadores. Segundo Grinevald (2000, p. 57), o tradicional era chamar de gênero os sistemas que dependem das características do sexo e toma o sistema de línguas europeias como padrão, enquanto classe nominal é um sistema de línguas mais “exóticas" a partir de um ponto de vista eurocêntrico.

Sistemas de classes nominal são bastante comuns em línguas da família Bantu. Por exemplo, afixos que denotam o gênero do referente são usados com base nas propriedades semânticas do nome para [+ humanos] e [+ animais], no caso do português por exemplo, a distinção de gênero é feita do mesmo modo independente 
se o referente é [+humano] ou não. Em línguas Bantu, as classes dos nomes são marcadas nos nomes, adjetivos, verbos e pronomes, os morfemas de classe de nomes também marcam a concordância singular/plural. Para Grinevald (2000), as classes nominais são morfossintaticamente complexas com muitas irregularidades. A autora chama atenção pela importância de se identificar o sistema de classe nominal em línguas amazônicas, pois elas aparentemente exibem esse sistema com regularidade.

De acordo com Kihn (2014), as propriedades de classes nominal devem ser comparadas com as propriedades dos sistemas de gênero conforme encontradas nas línguas europeias ou afro-asiáticas. Para o autor, o sistema de gênero difere do sistema de classe de nomes no que diz respeito à existência de 2 ou 3 gêneros (masculino, feminino e neutro) e em uma classificação baseada no sexo que é relevante para seres animados. No que diz respeito aos inanimados, Kihn (2014) afirma que a arbitrariedade parece ser muito mais presente do que nos sistemas de classes nominal. Mas, existem também bastante similaridades entre esses dois sistemas: Gênero e classe nominal podem desempenhar um papel de derivação, eles são predominantemente sufixos em algumas línguas. As línguas que apresentam classe nominal são frequentemente aglutinadas enquanto línguas com sistema de gênero são mais fusionais (KIHN, 2014). Interessante compreender que esses sistemas representam uma expressão gramatical da mente do falante, que é a classificação. Para Kihn (2014), ser um constituinte classificado é um traço inerente de um nome. Desse modo, os nomes são formalmente classificados de acordo com suas propriedades ontológicas (KIHN, 2014), diferentemente dos verbos. Portanto, um sistema de classe nominal e gênero pode ser um meio mais gramatical que uma língua pode usar para a categorização semântica de um nome.

Os outros dois sistemas inseridos na parte do "Lexical end of the Continuum" são os termos de medidas e de termos de classe. Grinevald (2000, p. 58) explica que os dois sistemas de classificação nominal são de naturezas diferentes. Para a autora, termos de 
medidas são lexicais no sentido que eles são semanticamente sintagmas nominais composicionais e analíticos e termos de classe são lexicais no sentido que operam como morfologia derivacional ou de composição no nível da palavra. Em consonância com Grinevald (2000), os termos de medidas existem em todas as línguas do mundo e expressam quantidades ou nomes massivos para o qual eles identificam unidades ou nomes contáveis onde especificam arranjos particulares.

Para Grinevald (2000, p. 58), nas línguas que exibem classificadores verídicos, os classificadores e os termos de medidas pertencem tipicamente a uma mesma categoria sintática, mas são consideradas separadamente como classificadores sortais e de medidas. Os classificadores sortais categorizam alguma característica inerente do referente, tal como o tamanho ou a forma. Grinevald exibe a diferença semântica entre esses dois tipos de classificadores.

Quadro 2 - Diferença entre classificadores de medidas e sortais.

\begin{tabular}{|c|c|}
\hline Classificador de Medidas & Classificadores Sortais \\
\hline Dois [ sacos de] laranjas & Duas [redonda] laranjas \\
\hline Um [pilha de] camisas & Uma [flexível, plana] camisa \\
\hline Três [círculos de] crianças & Três [humanos] crianças \\
\hline
\end{tabular}

Fonte: Grinevald (2000, p. 59).

Os termos de classe classificam morfemas que participam na gênese lexical de uma língua. Grinevald (2000, p. 59) explica que a diferença entre morfemas derivacionais e termos de classe que são usados em processos de composição nem sempre são discutidos e ambos acabam sendo rotulados como classificadores. De acordo com a autora, os termos de classe classificam morfemas de origem lexical clara e exibem degraus variados de produtividades no léxico de uma língua. Um dos termos de classe mais comuns em domínios semânticos é o mundo das plantas onde línguas especificam as diferenças de árvores e frutas por um processo de composição (GRINEVALD, 2000, p. 59). A língua Tariana analisada neste trabalho apresenta 
termos de classe, assim como outras línguas da família Arawák. Em muitos trabalhos, termos de classe e classificadores são confundidos dentro de uma classificação nominal, por isso a necessidade de saber distinguir um sistema do outro.

Os classificadores são um sistema intermediário entre o léxico e a gramática. Assim: “a característica do sistema de classificador é que eles constituem sistemas gramaticais de classificação nominal na extensão intermediária entre os extremos lexicais e gramaticais" (GRINEVALD, 2000, p. 61)². Desse modo, a característica do sistema de classificadores é que eles constituem um sistema gramatical de classificação nominal entre o léxico e a morfossintaxe. A seguir, o quadro 3 exibe a faixa intermediária dos sistemas de classificadores, conforme Grinevald (2000, p. 61).

Quadro 3 - Sistema de Classificação Nominal.

$<$ Lexical Gramatical>

Termos de Medidas Classe nominal-Gênero

Termos de classe

Classificadores

Medidas/Sortais

Fonte: Grinevald (2000, p. 61.)

Em consonância com Grinevald (2000), os classificadores constituem um sistema aberto de categorização nominal de origem lexical clara usada em construções morfossintáticas específicas. Por essa razão, o estudo do sistema de classificação nominal do léxico-gramatical-intermediário é conhecido como classificadores (GRINEVALD, 2000, p. 62). Grinevald (2000) faz a distinção de quatro tipos diferentes de classificadores que já estão bem estabelecidos na literatura, são eles: classificadores

\footnotetext{
2 The characteristic of classifiers systems is that they constitute grammatical system of nominal classification in the intermediate range between lexical and morphosyntactic extreme (GRINEVALD, 2000, p. 61)
} 
numéricos, nominais, genitivos (posse) e classificadores verbais. Contudo, ainda existem outros sistemas de classificadores que não são tão recorrentes em línguas do mundo: os locativos e classificadores com adjetivos. Todos esses tipos serão explicados na seção seguinte.

\section{A Morfossintaxe dos classificadores: um exemplo em línguas Arawák}

O estudo de classificadores ou de categorização nominal é um foco de interesse da tipologia funcional. Grinevald (2000) explica que ancorar o sistema de classificadores no nível morfossintático é apenas uma estratégia para compreender o fenômeno a partir de um aspecto formal. Conforme Aikhenvald (2000a), o termo "classificador" é usado para denotar um continuum de métodos de categorização do nome. Em consonância com Aikhenvald (2000a, p. 5), os sistemas de classe nominal, gêneros e classificadores têm sido objeto de investigação linguística em muitas línguas que exibem essas categorias. Desse modo, entendemos que todas as línguas do mundo necessitam categorizar os nomes e seus referentes em termos de propriedades semânticas e/ou sintáticas.

De acordo com Aikhenvald (2000a), as construções com classificadores são entendidas como unidades morfossintáticas (que podem ser sintagmas nominais de diferentes tipos como sintagmas verbais ou orações) que requerem a presença de um tipo particular de morfema e a escolha é ditada pelas características semânticas do referente do núcleo de um sintagma nominal (doravante SN). Existem quatro tipos de classificadores que são bastante recorrentes em línguas do mundo: numeral, nominal, genitivo (posse) e verbal, além dos locativos e classificadores com adjetivos, dêiticos ou em função anafórica. Desses tipos de classificadores, focaremos apenas nos quatro padrões mais recorrentes nas línguas do mundo e naqueles mais raros, os locativos e os adjetivos. As subseções abaixo resumem a definição desses classificadores e os 
exemplificam a partir das línguas de análise. Essas definições são de acordo com o estudo de Aikhenvald (2000a) e Grinevald (2000).

\subsection{Classificadores numerais}

Esse tipo é o mais comum encontrado em línguas do mundo. Os classificadores numerais aparecem contínuos ao número, em sintagmas nominais ou expressão de quantidade. Grinevald (2000, p. 63) explica que a denominação "numeral" é devido o contexto de quantificação em que ocorrem. A autora explica que esse tipo pode variar morfologicamente de um morfema livre para um afixo. Nas línguas Arawák selecionadas, eles são morfemas presos, predominantemente, sufixados no número ou no SN. Eles são infixados em algumas línguas como em Baure e em Palikur. Podem também ocorrer com demonstrativos. Esse tipo é bastante comum nas línguas do Sudoeste da Ásia (Tai, Birmanês), do Leste da Ásia (tal como o Chinês e Japonês), nas línguas da América e na Oceania. Segundo Aikhenvald (2000b), os classificadores de números não podem aparecer em qualquer constituinte fora do $\mathrm{SN}$, uma vez que não existe concordância entre o nome e outro constituinte.

\section{- Línguas do Norte-Arawák}

Esse tipo é bastante comum nas línguas do grupo Norte-Arawák, presente praticamente em todas as línguas. Os exemplos a seguir exibem o tipo de classificador numeral nas línguas selecionadas do Norte-Arawák.

(1) Achaguá (WILSON; LEVINSOHN, 1992, p. 62)

a. Báaji áaba-ahi um-CL:RECIPIENTE prato "um prato"

b. Chámacua Jáma-kua cubái

kubái 
dois-CL:LONGO

peixe

"Dois peixes"

c. Matálinai puíti

Matálĩ-nai

puíti

Três-CL:MAMÍFERO porco

"Três porcos"

(2) Baniwa de Içana (AIKHENVALD, 2007, p. 480-482)

a. Apa-api

maw-ipi

Um-CL:CÔNCAVO flecha-CL:LONGO/FINO

"Uma flecha"

b. Apa-ita

tinu

Um-CL:FEMININO,ANIMADO cachorro

"Uma cachorra"

c. Apa-ma

inazu

i-mutu-ka-ma

CL:FEMININO

Um-CL:FEMININO mulher IND-sair-DECL-

"Uma mulher que saiu"

Na língua Palikur, há classificadores do tipo sortal e de medidas. Todo nome em Palikur deve tomar um classificador numeral, portanto, classificadores numerais nessa língua são obrigatórios. A língua Palikur tem numerais de 1 a 10 e os classificadores são sufixados para todos os números, com exceção do numeral "2 (dois)" que são infixados.

(3) Palikur (AIKHENVALD; GREEN, 1998, p. 441-444)

a. Paha-bru upayan

Um-CL:GRUPO patos

"um bando de patos"

b. Pi-wok-na i-wak-ti

Dois-CL:MÃO-DOIS IND-mão-N.POSS

"Duas mãos"

c. Paha-p-ri awayg

Um-CL:ANIMADO-M homem 
“Um homem"

Em Resígaro, há classificadores que ocorrem junto com números. Os exemplos mostram que o próprio classificador se refere ao referente nominal apresentando uma função anafórica. Os exemplos em (4) exibem esse sistema de classificador na língua.

(4) Resígaro (ALLIN, 1976, p. 156-158)

a. Sá-hugí

Um-CL:CAMINHO

"um (caminho)"

b. Sá-koomí

Um-CL:ALDEIA

“Uma (aldeia)

c. Sá-mi hiitú

Um-CL:CANOA canoa

"Uma canoa"

d. Sá-?é aváana-Pé

um-CL:TRONCO árvore-CL:TRONCO

"um tronco da árvore"

As línguas do alto Rio Negro, Tariana e Warekena, exibem também o sistema de classificadores numéricos. Para a língua Warekena, apenas foi possível observar esse tipo de classificador, os outros tipos não foram encontrados na língua.

(5) Tariana (AIKHENVALD, 2000b)

a. Pa-kha ku-kha

Um-CL:CURVADO peixe.linha-CL:CURVADO

"Uma linha de pesca"

b. Pa-ita inaru

Um-CL:ANIMADO mulher

"Uma mulher"

c. Pa-ita a:pi

Um-CL: ANIMADO cobra

"Uma cobra" 
(6) Warekena (AIKHENVALD, 1998, p. 299)

$\begin{array}{lll}\text { a. Ni-fitua-hã ba-buya } & \text { peputfi } & \text { ninapa-mia } \\ \text { 3PL-Cortar-PAUS um-CL:TEMPO } & \text { dia } & \text { 3PL+terminar+PERF }\end{array}$ "Eles cortaram (as árvores) durante o dia e pararam"

b. Wa-hã ni-we Jia-wa ba-buya yafapua

Conj-PAUS 3PL-sair ficar-NONACC um-CL:TEMPO noite "Então, eles deixaram ficar uma noite"

c. Wa tia-wa peya peputfi

Conj. Ficar-nonacc um-CL-MASC dia

"Então, ele ficou (lá) uma noite"

Observamos no exemplo (6) que os classificadores além de ocorrerem com numerais, apresentam também uma função anafórica, já que eles retomam um referente que já foi introduzido no discurso. Aikhenvald afirma que a língua Warekena está perdendo o sistema de classificadores por conta da influência da língua Nheengatú.

Para a língua Wapixana, Santos (2006) sugere a partir das considerações de Payne (1991) que a própria forma do número "1 (um)" na língua contenha classificador. Os exemplos abaixo exibem os classificadores numerais em Wapixana.

(7) Wapixana (SANTOS, 2006, p. 119)

a. Pa-tso-ro

$$
\begin{aligned}
& \text { Um-CL:FALADO-F } \\
& \text { "uma palavra" }
\end{aligned}
$$

b. Ba-i- qa-?-ap

Um-mão-gênese-CL-PTT-CL:EXTENSÃO

"Um"

c. Pa-mi-ka?i-ta-m-ki-?

Um-antes-mãe-gênese-?-cada-CL:PTT (Partitivo)

"quatro"

Das 8 línguas selecionadas do grupo Arawák do Norte, apenas a língua Garifuna não apresenta esse sistema ou este ainda não foi descrito com detalhe. No 
que diz respeito às línguas do Grupo Sul-Arawák, apenas encontramos classificadores numerais descritos em Baure, Nanti e Paresi como podemos observar nos exemplos a seguir.

- Línguas do Sul-Arawák

(8) Baure (DANIELSEN, 2007, p. 139-142)

a. Roti 'Roenisa popoš him

Roti ro=inisa po-po-š him

3SGM 3SGM=PEIXE um-CL:PEQUENO-um Peixe

Pitir piti'

Pitir piti

2SGP 2SG

“Ele pegou um peixe (pequeno) para você"

b. Popoš kočopon

Po-po-š kočopon

Um-CL:PEQUENO-UM jacaré

“Um jacaré (pequeno)"

c. Peš rekirok/

peš mokovis

Po-e-š rekirok po-e-š mokovis

Um-CL:NÃO DOCE-um tucumã Um-CL:NÃO DOCE-um abóbora

"Um tucumã, uma abóbora"

Para a língua Nanti (Campa) apenas foi verificado um exemplo com classificador numeral. Michael (2006, p. 8) explica que em contextos morfossintáticos os classificadores são infixados com os números em Nanti.

(9) Nanti (MICHAEL, 2006, p. 8)

a. Pitekiti

Pite-ki-ti

Dois-CL:PEQUENO.REDONDO-DURO-DOIS

“Dois (predicado de, por exemplo, um par de contas (miçangas)" 
Em Paresi, os classificadores podem ser atachados a um numeral e também a um demonstrativo exibindo uma função dêitica. Os exemplos a seguir mostram os classificadores com numerais nessa língua.

Paresi (BRANDÃO, 2015, p. 61; BRANDÃO, 2016, p. 279)

a. Atya-taotse hanama-taotse

Árvore-CL:PEDAÇOS três-CL:PEDAÇOS

"Três pedaços de madeira"

b. Eze hanama-katse atya-katse

DEM três-CL:COMPRIDO árvore-CL:LONGO/COMPRIDO

"Esses são três varas"

c. Hanama-katse kirane-ze

Três-CL:COMPRIDO ser.pequeno-NMLZ

"Três varas são pequenas"

Entre as 15 línguas analisadas, observamos que os classificadores numerais estão presentes em 10 línguas. Podemos observar que, na grande maioria, os classificadores de números são sufixados, contudo, em Baure, Palikur e Nanti eles são também infixados.

\subsection{Classificadores nominais}

Para Aikhenvald, os classificadores nominais caracterizam o nome e coocorrem com um SN. Eles são um tipo de sistema de classificador bem reconhecidos nas línguas da Austrália e Mesoamericanas. Eles podem ser conhecidos na literatura como "classificadores genéricos" ou apenas "genéricos". De acordo com a autora, a propriedade conceitual de um classificador nominal é que sua presença em um SN é independente de outros constituintes dentro ou fora dele, o escopo do classificador nominal é um SN. Aikhenvald (2000a, p. 81) elenca algumas propriedades dos classificadores nominais que são: 
a) A escolha de um classificador nominal é baseada na semântica;

b) Línguas podem permitir a coocorrência de vários tipos de classificadores nominais dentro de um SN;

c) Um nome pode ser usado com diferentes classificadores, com uma mudança no significado;

d) O tamanho do inventário de classificadores nominais pode variar de língua para língua e, consequentemente, classificadores nominais podem ser gramaticalizados em extensões variadas;

e) Classificadores nominais são frequentemente usados anaforicamente que podem gramaticalizar e marcar funções sintáticas.

Todas essas propriedades são importantes para compreender esse sistema de classificador dentro das línguas Arawák selecionadas. Principalmente, a propriedade (v), uma vez que a maioria dessas línguas também utiliza o classificador para sentidos anafóricos. De acordo com Grinevald (2000, p. 64), os classificadores nominais são predominantemente realizados com morfemas livres que estão em um sintagma nominal (SN) ao lado do próprio nome ou dentro dos limites dos SN com outros determinantes do nome. Contudo, em algumas línguas, os classificadores nominais podem sofrer gramaticalização e redução fonológica e tornam-se afixos para os nomes. Nas línguas de análise, apenas identificamos, mesmo que preliminarmente, três línguas com sistema de classificação nominal: Ashénika Perené, Paresi e Tariana. Contudo, se aplicarmos os classificadores nominais como morfemas derivacionais, podemos também elencar as línguas Baniwa de Içana, Mehináku e Waujá.

\section{- Línguas do grupo Norte-Arawák}

Iniciando a análise com a língua Tariana que faz parte do grupo Norte-Arawák, verificamos que há uma descrição (ainda que superficial) sobre classificadores 
nominais. Aikhenvald afirma que esses classificadores são sufixados ao nome e especifica a sua propriedade semântica. Assim, "todos os classificadores são usados com sufixos nominais derivacionais" (AIKHENVALD, 2000b, p. 97) e eles não podem ser usados anaforicamente ${ }^{3}$. Nesta língua, os classificadores nominais quando usados sobre um nome com um referente inanimado têm o efeito de focar em uma característica adicional de um nome, individualizando o seu referente. A autora explica que os nomes com referentes inanimados são intrinsicamente não marcados para número quando usado sem o sufixo classificador, mas, caso o sufixo classificador seja adicionado, os nomes adquirem uma visão singular e podem ser pluralizados.

Aikhenvald (2000b) apresenta como exemplo episi que significa "ferro com substância" e ele não pode ser marcado para número e não pode ser pluralizado (*episi-pe $\rightarrow$ ferro + pl). Quando um classificador nominal é adicionado, ele adquire uma semântica mais concreta e é compreendido como se referindo a um objeto especificado para sua forma: episi-kha (Ferro-CL: Curvado $\rightarrow$ "arame de ferro”), episipi (ferro - CL:longo $\rightarrow$ "pedaço de ferro longo"). Para Aikhenvald a escolha de um classificador é semanticamente transparente em alguns casos. No entanto a relação semântica entre um classificador nominal e um nome não é tão óbvia em outras línguas. Os classificadores em Tariana podem também desempenhar uma função derivacional, como podemos verificar nos exemplos em (11).

(11) Tariana (AIKHENVALD, 1994, p. 216)
a. Episi "Ferro, metal" $\rightarrow$ episi-aphi Metal
Metal-CL:OCO
"panela de metal"
b. Heku-na $\rightarrow \quad$-heku-ita $>$ hekuta Madeira-CL:VERTICAL-madeira-CL:ANIMADO "remo"
c. Heku-da
Madeira-CL:REDONDO "Fruta da árvore"

\footnotetext{
${ }^{3}$ Neste caso, os classificadores nominais não podem ser realizados como anáforas em Tariana o que é difere da propriedade (v) exposto por Aikhenvald.
} 
Em Baniwa de Içana também há um exemplo de classificadores desenvolvendo uma função derivacional como podemos constatar no exemplo em (12).

(12) Baniwa de Içana (AIKHENVALD, 2007, p. 479)

tipara-api

Metal.Obj-CL:BURACO/REDONDO

"Essa panela é minha" nu-daz-api

1SG.POSS-CL:BURACO/REDONDO

\section{- Línguas do Grupo Sul-Arawák}

Em Ashéninka Perené, existe classificadores nominais. Mihas (2010) afirma que os classificadores nominais nesta língua são presos diretamente na raiz nominal. Assim como Tariana, não desempenham uma função anafórica. Os classificadores nominais específicos como os nomes de acordo com sua forma, dimensionalidade e consistência, eles também podem desempenhar uma função derivacional. Os exemplos em (13) exibem os classificadores nominais em Ashénika Perené.

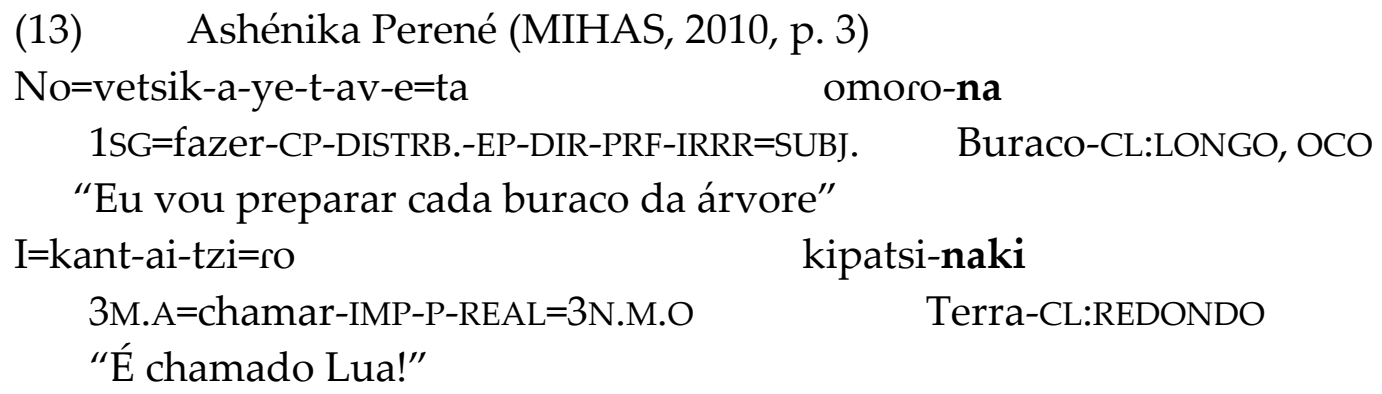

Em Paresi, os classificadores podem ocorrer com nomes. Brandão (2015, p. 59) explica que os classificadores em raiz nominal funcionam como elementos derivacionais em alguns compostos e eles podem ser lexicalizados em nomes para introduzir itens culturais. Assim sendo, eles derivam nomes a partir de outros nomes que derivam novas palavras, como podemos observar no exemplo em (14) abaixo. 


$$
\text { Paresi (BRANDÃO, 2015, p. 60) }
$$
a. Kore-natse
b. kote-tse
Arma-CL:CILINDRICO
Arma-cl:pequeno
"Arma"
"pólvora"

b. Itimi-za

Fogo-CL:LÍQUIDO

"Gasolina"

De acordo com Aikhenvald (2000a, p. 84), os classificadores nominais não são semanticamente redundantes e o seu comportamento é similar às funções derivacionais de marcadores de classes de nomes. Se formos aplicar a função derivacional dos classificadores nominais como ocorre em Tariana, Baniwa de Içana, Ashénika Perené e Paresi, as línguas Mehináku e Waujá vão apresentar também esse sistema. Os exemplos em (15) mostra os classificadores com função derivacional em Mehináku e em (16) em Waujá.

(15) Mehináku (CORBERA MORI, 2012, p. 134-135)
a. Ule:-pe
Mandioca-CL:MASSA
b. Ata-pana
Árvore-CL:FOLHA
"folha, dinheiro"
c. Tulü-ti
Orelha-CL:SEMENTE
"Brinco"

"beijú (Lit.Massa de Mandioca)"

(16) Waujá (POSTIGO, 2014, p. 153-155)
a. [jala'ki-ja]
/jala'ki-Ga/
Preto-CL:LÍQUIDO "café"
b. [i kitsi-tyãna]
/i'kitsi-kana/ 
Nariz:CL:RECIPIENTE

c. [atai, tai' tsari]

/'ata-i'tai-'tari/

"árvore.semente-CL:ESFÉRICO "semente da árvore"

d. [,ata'pãna]

/'ata-pana/

Árvore-CL:FOLIFORME "telhado"

"folha/dinheiro"

Nos exemplos acima, observamos os classificadores desempenhando uma função derivacional, ou seja, além de exibirem um aspecto semântico dos seus referentes, sintaticamente, eles podem formar novos itens lexicais. Formar novas palavras é uma das funções dos classificadores nominais, então, podemos sugerir que Baniwa de Içana, Mehináku e Waujá exibem classificadores nominais.

\subsection{Classificadores genitivos, possuídos e relacional}

De acordo com Aikhenvald (2000a, p. 125), existem três formas de categorizar nomes em construções possessivas: (i) categorizando um nome possuído; (ii) categorizando a natureza semântica da relação entre o possuidor e o possuído; e (iii) categorizando o possessor. Para a autora, os três tipos de categorização em construções possessivas são relativamente independentes um do outro. Grinevald (2000) não faz uma distinção de classificadores em construções possessivas, mas argumenta que esse tipo de categorização tem diferentes denominações: atributivo, genitivo, relacional ou possuidor. Eles não envolvem concordância (AIKHENVALD, 2000a) e assim como outros classificadores categorizam os nomes em termos de animacidade, de forma, de tamanho e de estrutura.

Esses classificadores são geralmente afixados para marcar a posse e semanticamente classifica o nome possuído. Grinevald (2000) explica que esse sistema de classificador seleciona um conjunto limitado de nomes das línguas para classificação. Aikhenvald (2000a) argumenta que os classificadores possuídos não 
caracterizam o tipo de relação entre o possuidor e o possuído, ou seja, eles não necessitam estar inter-relacionados ou depender da distinção entre posse alienável e inalienável. Contudo, em algumas línguas, esse tipo de classificador pode ser usado apenas com nomes alienavelmente possuídos. Esse tipo de classificador é encontrado em línguas da Oceania. Das línguas Arawák selecionadas, a constatação se deu em Baniwa de Içana, Garifuna, Palikur, Tariana e Wapixana (Grupo Norte-Arawák).

\section{- Línguas do Grupo Norte-Arawák}

As línguas do grupo Norte-Arawák apresentam com mais predominância esse tipo de classificador. A língua Baniwa de Içana exibe o classificador em construções possessivas como podemos verificar nos exemplos em (17).

$$
\text { Baniwa de Içana (AIKHENVALD, 1994, p. 201; AIKHENVALD, }
$$
2007, p. 479)

a. Kiniki nu-cka-phi

Roça 1SG-POSS-CL:ESP

"a roça é minha"

b. tyipara-api nu-dza-api metal.obj-cl:oco 1sg-poss-cl:oco "Esta panela é minha"

Para a língua Garifuna, apenas identificamos no trabalho de Larsen-Haurholm (2016) os classificadores possessivos. O autor refere-se aos classificadores genitivos como relacional. De acordo com Aikhenvald (2000a), os classificadores relacionais diferem dos outros tipos de classificadores. Uma vez que apenas caracterizam uma relação possessiva entre os nomes, eles também não envolvem concordância e são quase sempre encontrados em construções de posse alienável. Em Garifuna, os classificadores relacionais são recorrentes em nomes alienavelmente possuídos, como podemos verificar nos exemplos em (18). 
(18)

a. N-éygan Garifuna (LARSEN-HAURHOLM, 2016, p. 59)

1SG-CL:NÃO CARNE Banana.massa

"Minha banana"

b. N-éygan dáni

1SG-CL:NÃO CARNE Mandioca

"Minha Mandioca"

c. N-úyi údereü

1sg-CL:CARNE peixe

"Meu peixe"

Na língua Palikur, nem todos os nomes podem tomar um classificador possessivo (AIKHENVALD; GREEN, 1998), colaborando com a hipótese de Grinevald (2000) que há um conjunto limitado de nomes que recebem esse tipo de classificador e eles são apenas usados em nomes possuídos alienavelmente. Podemos sugerir também que esse tipo de classificador pode ser relacional, já que, na língua, apenas verificamos os classificadores em posse alienável. Os exemplos em (19) exibem os classificadores em construções possessivas em Palikur.

$$
\text { Palikur (AIKHENVALD; GREEN, 1998, p. 490) }
$$
a. Gi-pig Pewru
3SGM-CL: ANIMAL
Cachorro
"Seu cachorro"
b. Pi-mana uwas
2SG-CL: FRUTA Laranja
"Sua laranja"

Diferentemente de Palikur que os classificadores só ocorrem com nomes alienáveis, na língua Tariana, os morfemas classificadores de construções possessivas ocorrem tanto em nomes alienáveis quanto em nomes inalienáveis, como podemos observar nos exemplos em (20). 
(20) Tariana (AIKHENVALD, 2000b)
a. Nu-ya-da nu-hwida
1SG-POSS-CL: REDONDO 1SG-cabeça
"minha cabeça" (posse inalienável)
b. Nu-ya-pi
sipi $i$
1SG.POSS-CL:LONGO zarabatana
"minha zarabatana" (posse alienável)

Verificamos que o SN sīpi "Zarabatana" diferente do Hwida "cabeça” não recebe marcação de posse. Aikhenvald (2000b) afirma que em Tariana os classificadores de posse podem ser usados em construções anafóricas. A última língua do grupo NorteArawák que apresenta classificadores genitivos é a Wapixana. Os exemplos em (21) exibem esse tipo de classificador nessa língua.

(21) Wapixana (SANTOS, 2006, p. 121-123)
a. Suzaz await-a-n wa-puna:
Soldado impedir-EP-MI 1PL-CL:EXTENSÃO
"O soldado impediu (nosso caminho)"

Podemos observar no exemplo (21) que o classificador está sendo utilizado para retomar um referente no discurso. Santos (2006) assume que nessa construção, o classificador está em um sentido pragmático. Diferente das outras línguas de análise, os classificadores genitivos na língua Wapixana apenas são utilizados na ausência do nome referente, como podemos constatar nos outros exemplos adiante.
b. ũ-dap sabi-a-n ipei 1-CL:HABITAÇÃO gotejar-EP-MI todo "goteja toda em minha casa"
c. ǔ-fimak 1-CL-FLEXÍVEL "Minha rede"


Não verificamos, em Wapixana, classificadores com nomes inalienáveis, isso pode colaborar com a hipótese de que os classificadores em construções de posse nessa língua são categorizados como relacionais conforme às considerações de Aikhenvald (2000a).

As línguas do grupo Sul-Arawák selecionadas para este trabalho não exibem descrições de classificadores em construções genitivas, sendo um aspecto recorrente apenas nas línguas do grupo Norte-Arawák.

\subsection{Classificadores verbais}

Para Grinevald (2000), ao contrário dos tipos de classificadores mencionados acima que ocorrem dentro de um SN, o classificador verbal é encontrado dentro do verbo. A autora argumenta que esse tipo de classificador não classifica o verbo, mas sim seus argumentos nominais (internos ou externos). Esse tipo de classificador tem sido descrito em línguas da América do Norte e da Austrália. De acordo com Grinevald (2000, p. 67), existem dois tipos básicos de classificadores verbais: o primeiro é uma construção de classificador incorporado que ainda é reconhecível como um nome genérico. A autora ainda pontua que os classificadores desse tipo de incorporação ainda são semelhantes aos classificadores de nomes. O outro tipo é mais semelhante aos classificadores de números por conta da sua semântica. Os classificadores verbais, assim como os de números, são também recorrentes nas línguas selecionadas, sendo presente em nove línguas dessa família. Em todas essas línguas, os classificadores verbais classificam algum argumento nominal do verbo e são encontrados dentro da raiz verbal. 


\section{- Línguas do grupo Norte Arawák}

Das línguas que pertencem ao grupo Norte-Arawák os classificadores verbais são presentes em Baniwa de Içana, Palikur, Tariana e Wapixana, como podemos verificar nos exemplos a seguir.

Baniwa de Içana (AIKHENVALD, 2007, p. 480-484)

a. Hrie tipara-api pi-ckana-kazu-api

PROX.DEM.NON.FEM-SG metal.OBJ-CL:OCO 2SG-cozinharPURP-CL:OCO

"Esta panela é para você cozinhar"

b. Aţiãri pi-a-nita posata

Homem 2sg-RECEBER-TOP.ADV-CL:NON.FEM.ANIM dinheiro

"O homem recebeu dinheiro de você"

c. Apa-kha

Um-CL:CURVADO estrada Grande.ADJ-CL:CURVADO
pi-a-ni-kha
2sg-ir-TOP.ADV-CL:CURVADO
"Uma grande estrada curvada é para você ir"

(23) Palikur (AIKHENVALD ; GREEN, 1998, p449-450)

a. Gu-spri puhi-pti-ye 3SGF.pena Preto-V-CL: IRREGULAR-DURNF.

"As penas dele (do pássaro) são pretas por toda parte/ são completamente pretas"

b. $\mathrm{Ig}$

pituk-mina-wa a-r-i-w 3MASC Quebrar-V-CL:VERTICAL-REFL 3n-ep-longe "Ele quebrou (ele mesmo) para fora do cordão" (Lit. Ele quebrou suas próprias partes verticais, ou seja, braços ou pernas que foram amarradas por um cordão)."

$$
\text { Tariana (AIKHENVALD, 2000b) }
$$

a. I:nari di-naku-ni-ma-pe-se ihya

Mucura 3SGNF.enganar-TOP.ADV-CL:FEM-PL-RESULT 2pl

"Vocês duas foram (mulheres) enganadas pela mucura (disse um pássaro para uma mulher mística) 
b. Ne-se

$$
\text { di-musu } \quad d y-u k a
$$

pani-si

CONJ.LOC 3SGNF.sair 3SGNF.chegar

casa-NPOSS

di-uma-pidana

diha aria-hyu-dapana

3SGNF.observar.PARA-REM.P.INFR

Ele ficar-PURP-CL:HAB

"Então ele foi e observou uma casa para ele mesmo viver"

Wapixana (SANTOS, 2006, p. 125)

a. $\tilde{u}-n i z u-b-a: n-a-n$ kan-iz-bi?

1-tipiti-CL-MASSA-INTER-EP-MI mandioca-TCL:NÃO.DISCRETOTCL:MASSA

"Espremo a massa a mandioca no tipiti"

b. ü-t-iz-ni:

$\mathrm{w}-\mathrm{i}-\mathrm{n}$ wadidi-Pu

1-beber-CL:NÃO DISCRETO-NPRES água-TCL:NÃO DISCRETO frioADJ

"Eu bebi água"

\section{- Línguas do grupo Sul Arawák}

Das línguas que pertencem ao grupo Sul-Arawák, os classificadores verbais são mais predominantes que os de número, ocorrendo em cinco línguas: Ashéninka Perené, Baure, Nanti , Paresi e Yawalapiti. Os exemplos a seguir exibem esse sistema nas línguas de análise do Grupo Sul Arawák.

(26) Ashéninka Perené (MIHAS, 2010, p. 3)

a. Osheki $y=a$ ashit-a-poroki=vai-tzi

QUANTIF. $\quad 3 \mathrm{M} . \mathrm{S}=$ molhar-EP-CL:GRUPO-DUR-REAL

"Muitos [artesanatos] ficaram molhados"

b. Hiti

$i=s a i k$-a-poroki-tzi $=r a$

LOC.DEM

3m.s-sentar.sobre-CL:GRUPO-REAL=ADV

"Ele está sentado em um saco de ossos, ali"

c. Naina $\mathrm{o}=\mathrm{n}=$ koye-ki-t-ah-aty-e

Esposa 3N.M.S=IRR-colher-CL:PEQUENO, REDONDO-EP-REGR-PROGIRR

"Minha esposa vai colher grãos de café" 
(27) Baure (DANIELSEN, 2007, p. 139-149)
a. Vehpaw
to etip
$\mathrm{Vi}=$ eh-po-a-wo
to etip
1PL=LAVAR-CL:PEQUENO-LK-COP
ART mandioca-amido
"Nós lavamos a farinha de mandioca"

b. Rakpiaw

$$
\begin{aligned}
& \text { Ro=ak-pi-a-wo } \\
& \text { 3SGM=CANTAR-CL:PALAVRAS-LK-COP } \\
& \text { "Ele está cantando" }
\end{aligned}
$$

(28) Nanti (MICHAEL, 2006, p. 8-10)
a. Ikamahitake
i-kam-a-hi-t-ak-i
3ms-morrer-VEP-CL:INSETO-CEP-PERF-IRR.REA
"Ele morreu (referência formigas, lagartas, vespas)"

b. Omakakitatanake

O-maka-kita-t-na-ak-i

3NMS.apodrecer-CL:ESTEIRA.PLANO-CEP-TODA-PERF-IRR.REA

"Apodreceu (referência à esteira)"
c. Pabobuseti (pisapiro)
Pi-abobu-se-t-i pi-sapiro
2s-costurar-CL:MASSA, MORFO-CEP-REA.IRR 2P-Roupa
"Estás costurando tua roupa"

(29) Paresi (BRANDÃO, 2015, p. 60; BRANDÃO, 2016, p. 280)

a. Wi=riko-tse-koa-t=ene

$1 \mathrm{pl}=$ cortar-cl:pequeno-cl:plano-th=3

"nós cortamos em pedaços pequenos"

b. Nilva $\varnothing=$ itsoa-tse-hena

Nilva $\quad 35 G=e n t r a r-C L: P E Q U E N O-T R S$

"Nilva (a baixinha) entrou"

c. $\varnothing=$ holikoa-natse-tya

3SG=dançar-CL:CILÍNDRICO-TH

"Dançou em cima do tronco"

A língua Yawalapiti aparentemente exibe o classificador verbal, mas apenas foi encontrado um exemplo, como podemos verificar em (30) a seguir: 
(30) Yawalapiti (MIJUCA, 1992, p. 48)
a. Ata-pana ku'ka 'iru kana-pa'na
Árvore-CL:FOLHA PAS
DEM.FEM
morrer-CL.FOLHA
"A árvore seca (a folha que morreu) está aí"

Podemos observar que essas línguas apresentam classificadores incorporados nos verbos. Aikhenvald argumenta que os classificadores verbais aparecem no verbo, categorizando o referente do seu argumento em termos de sua forma, consistência, tamanho, estrutura, posição e animacidade. A autora explica que os classificadores sempre se referem ao argumento predicativo (geralmente, o sujeito em uma oração intransitiva ou objeto em uma oração transitiva) e essa escolha é predominantemente semântica.

\subsection{Classificadores locativos e adjetivos.}

Os tipos de classificadores apresentados acima são os mais comuns e mais conhecidos na literatura sobre classificadores. Contudo há outros tipos que ainda não foram descritos de forma detalhada e isso se deve ao fato de que eles podem ser tipos de classificadores raros nas línguas. Nas línguas Arawák selecionadas, verificamos classificadores locativos e com adjetivos.

Segundo Aikhenvald (2000a, p. 173), os classificadores locativos são morfemas que ocorrem em sintagmas nominais locativos e sua escolha é determinada pela característica semântica do nome envolvido. Aikhenvald afirma que esse tipo de classificador é o argumento de uma adposição locativa. Classificadores desse tipo são raros. Nas línguas estudadas, apenas encontramos esse tipo em Palikur (Grupo NorteArawák), Baure e Mehináku (Grupo Sul-Arawák). 


\section{- Línguas do Grupo Norte-Arawák}

A língua Palikur exibe um grupo de morfemas que funcionam como adposição locativa significando "sobre" e "em". Aikhenvald e Green (1998) afirmam que a escolha depende da forma e do limite do núcleo nominal. Em Palikur, os classificadores locativos são baseados na forma, dimensionalidade e limitações. Os exemplos em (31) exibem esse tipo de classificador nessa língua.

$$
\text { Palikur (AIKHENVALD; GREEN, 1998, p. 457) }
$$

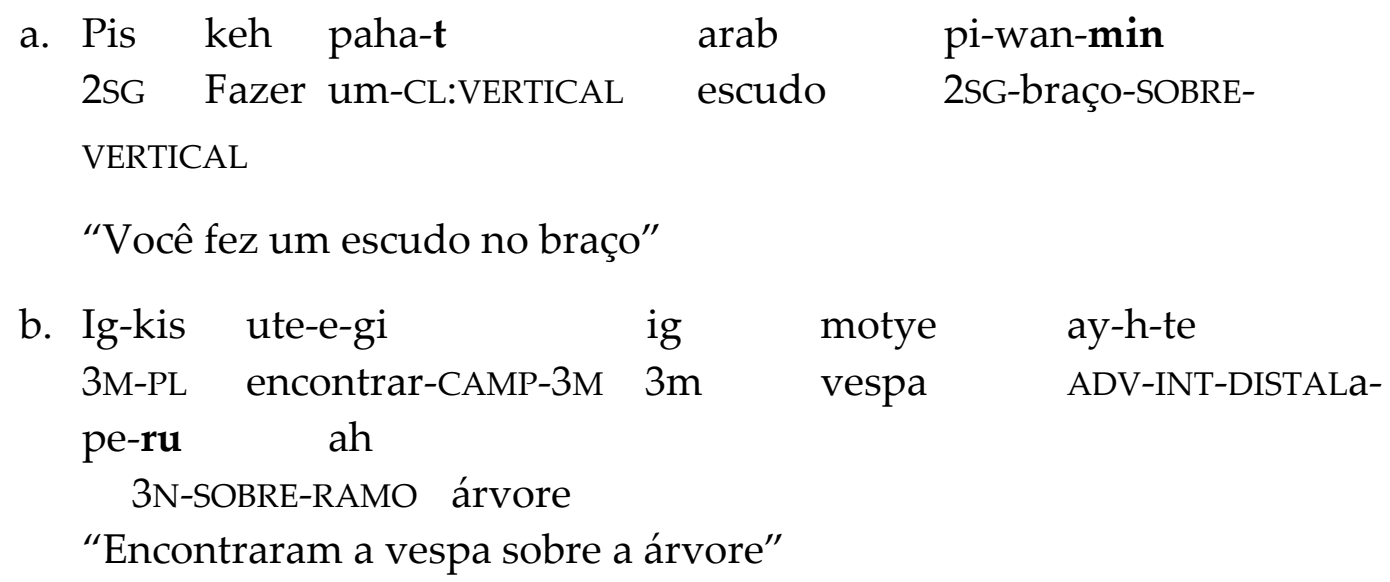

\section{- Línguas do grupo Sul-Arawák}

Identificamos duas línguas deste grupo que apresentam classificadores com sentido locativo: Baure e Mehináku.

Danielsen (2007), para a língua Baure, apresenta apenas um exemplo de classificador locativo, o -imir "face, frente" que não pode ser utilizado com números, como podemos verificar no exemplo em (32).

$$
\text { Baure (DANIELSEN, 2007, p. 150) }
$$

a. Siyimiri-ye
Siy-imir-ye
Cadeira-CL:FACE-LOC
"Na frente da cadeira" 
Na língua Mehináku, há também um tipo de classificador que tem a função locativa, o morfema -taku como podemos verificar nos exemplos em (33).

$$
\text { Mehináku (CORBERA MORI, 2007, p. 257) }
$$
a. Keni-taku
b. Enu-taku
Terra-CL:LOCATIVO
Céu-CL:LOCATIVO
"Na terra" "no céu"

Outro tipo de classificador encontrado em línguas do mundo é o que vem junto com adjetivos. Esse tipo parece ser bem mais recorrente nas línguas do grupo SulArawák selecionadas do que nas línguas do Norte-Arawák, desse último grupo, apenas Baniwa de Içana apresenta esse tipo. Já nas línguas Sul-Arawák, encontram-se classificadores com adjetivos em Baure, Nanti e, aparentemente, em Yawalapiti.

\section{- Línguas do grupo Norte-Arawák}

a. Apa-ita

$$
\text { Baniwa de Içana (AIKHENVALD, 2007, p. 487) }
$$

$$
\begin{aligned}
& \text { Um-CL:NON.FEM.ANIM IND.osso grande.ADJ- } \\
& \text { CL:N.FEMININO.ANIMADO } \\
& \text { "Um grande osso (parece como uma parte de um corpo } \\
& \text { humano)" }
\end{aligned}
$$

b. Apetgia manakhe

Um+NUM-CL:PUNHADO.PEQUENO.FRUTA açaí.fruta
maka-dari
nu-de:-ni-da
grande.ADJ-CL:GENÉRICO
“Um grande punhado de açaí foi / é tomado por mim”.

- Línguas do grupo Sul-Arawák

a. $\mathrm{Te}$

in
Baure (DANIELSEN, 2007, p. 148)

račkow in - morok. $\begin{array}{lll}\text { Te } & \text { čo-se } & \text { ro=ačko-wo in marok } \\ \text { DEM.1M } & \text { grande-CL:OVAL } & 35 G M=\text { ser.completo-COP }\end{array}$ morok 
in

morok

água chicha

"Este grande copo/garrafa está cheio de chicha (ou água)"

b. $\check{C} a$

$\begin{array}{lcc}\text { Čo-aso } & \begin{array}{c}\text { monči-wo=ni } \\ \text { criança-COP-1SG }\end{array} & \text { ni=kač } \\ \text { Grande-CL:TEMPO } & \text { šonoki-ye } \\ \text { Viyonpoek } & \text { šonoki-ye } \\ \text { vi=yonpoek } & \text { caminho-LOC } & \end{array}$

"Há muito tempo, quando eu era criança, fui andando descalço por esse caminho"

(36) Nanti (MICHAEL, 2006, p. 8)

a. Kirahariki

\author{
Kirara-ki-ri \\ Vermelho-CL:PEQUENO-VERMELHO \\ "miçangas"
}

Na língua Yawalapiti, podemos observar que os classificadores sempre estão afixados a um adjetivo que está caracterizando o referente. Desse modo, podemos sugerir que nessa língua os classificadores também ocorrem com adjetivos como ilustram os exemplos em (37).

$$
\text { Yawalapiti (MIJUCA, 1992, p. 47) }
$$

a. Ma'tfi ju'ma-ti

Milho verde-CL:LONGO

"milho verde"

b. a'maka autsa-ka

Rede novo-CL:PLANO

"Rede nova"

c. a'maka

$$
\text { kitsiju-ka }
$$

Rede forte-CL:PLANO

"Rede forte"

\footnotetext{
${ }^{4}$ Em Nanti apenas foi encontrado esse exemplo com classificadores com adjetivos, nesse caso aparentemente parece que o classificador está derivando um nome, mas infelizmente por conta de falta de dados é impossível afirmar se os classificadores em Nanti podem também execer a função de morfemas derivacionais.
} 


\section{Tendências Tipológicas dos classificadores nas línguas de análise}

Para Grinevald (2000), a proposta da tipologia de classificadores é concentrada em uma perspectiva tipologia funcional que leva em consideração aspectos funcionais, morfossintáticos e semânticos de uma determinada língua.

Observamos, mesmo preliminarmente, que as línguas Arawák selecionadas exibem classificadores que designam sempre uma propriedade do nome e que eles podem ocorrer em diferentes aspectos gramaticais com sistema numérico, nome, posse, dentro do verbo, etc. Os classificadores também podem designar propriedades locativas e ocorrer com adjetivos.

Para este trabalho, apenas focalizamos os classificadores de números, nominais, genitivos, verbais, locativos e adjetivos, sendo estes últimos os mais raros. Diante disso, foi possível postular duas tabelas que apresentam um padrão preliminar dos sistemas de classificadores das línguas selecionadas. A tabela (1) refere-se os classificadores encontrados nas línguas do Grupo Norte-Arawák e a tabela (2) diz respeito às línguas do grupo Sul-Arawák 5 .

Tabela 1 - Línguas Arawák do Norte.

\begin{tabular}{|c|c|c|c|c|c|c|}
\hline Língua & CL.Num & CL.Nom & CL. Gen & CL.Verb & CL.Loc & CL. Adj \\
\hline Achaguá & $x$ & & & & & \\
\hline Baniwa de Içana & $x$ & $x(?)$ & $x$ & $x$ & & $x$ \\
\hline Guarifuna & & & $x$ & & & \\
\hline Palikur & $x$ & & $x$ & $x$ & $x$ & \\
\hline Resígaro & $x$ & & & & & \\
\hline Tariana & $x$ & $x$ & $x$ & $x$ & & \\
\hline Warekena & $x$ & & & & & \\
\hline Wapixana & $x$ & & $x$ & $x$ & & \\
\hline
\end{tabular}

Fonte: elaborada pela autora.

\footnotetext{
${ }^{5}$ Os que estão marcados com $x$ ? na tabela são línguas que aparentemente apresentam esse tipo de classificador, mesmo que eles não tenham sido descritos com propriedades morfossintáticas.
} 
Tabela 2 - Línguas Arawák do Sul.

\begin{tabular}{|c|c|c|c|c|c|c|}
\hline Língua & CL.Num & CL.Nom & CL. Gen & CL.Verb & CL.Loc & CL. adj \\
\hline Ashénika & & $\mathrm{x}$ & & $\mathrm{x}$ & & $\mathrm{x}$ \\
\hline Baure & $\mathrm{x}$ & & & $\mathrm{x}$ & $\mathrm{x}$ & $\mathrm{x}$ \\
\hline Mehináku & & $\mathrm{x} ?$ & & $\mathrm{x}$ & & \\
\hline Nanti & $\mathrm{x}$ & & $\mathrm{x}$ & & \\
\hline Paresi & $\mathrm{x}$ & $\mathrm{x}$ & & & & $\mathrm{x}(?)$ \\
\hline Waujá & & $\mathrm{x} ?$ & & $\mathrm{x}$ & & \\
\hline Yawalapiti & & & & & & \\
\hline
\end{tabular}

Fonte: elaborada pela autora.

Observando as duas tabelas, podemos constatar que há uma distribuição bastante ampla e diversificada do sistema de classificadores nas línguas Arawák. Por exemplo, os classificadores de números parecem ser bem mais predominantes nas línguas do grupo Norte-Arawák e não tão recorrentes nas línguas do grupo SulArawák. Os classificadores nominais, ao contrário, são mais presentes nas línguas do grupo Sul-Arawák. Os classificadores genitivos são mais recorrentes nas línguas do Norte do que nas línguas do Sul. Os classificadores verbais são bastante predominantes tanto nas línguas do Norte quando nas do Sul. Os tipos locativos são raros em todas essas línguas, até mais raros que os classificadores com adjetivos. A tabela (3) exibe a tipologia morfossintática dos classificadores sem a divisão das línguas em grupos, para que assim possa se ter uma visualização melhor desse fenômeno na família Arawák. 
Tabela 3 - Padrões Tipológicos dos classificadores das línguas Arawák.

\begin{tabular}{|c|c|c|c|c|c|c|}
\hline Línguas & CL.NUM & CL.NOM & CL.GEN & CL.VERBAL & CL.LOC & CL.ADJ \\
\hline Achaguá & $x$ & & & & & \\
\hline Ashénika & & $x$ & & $x$ & & \\
\hline Baniwa & $x$ & x (?) & $x$ & $x$ & & $x$ \\
\hline Baure & $x$ & & $x$ & $x$ & $x$ & $x$ \\
\hline Garifuna & & & $x$ & & & \\
\hline Mehináku & & $x(?)$ & & & $x$ & \\
\hline Nanti & $x$ & & & $x$ & & $x$ \\
\hline Palikur & $x$ & & $x$ & $x$ & $x$ & \\
\hline Paresi & $x$ & $x$ & & $x$ & & \\
\hline Resígaro & $x$ & & & & & \\
\hline Tariana & $x$ & $x$ & $x$ & $x$ & & \\
\hline Warekena & $x$ & & & & & \\
\hline Wapixana & $x$ & & $x$ & $x$ & & \\
\hline Waujá & & $x(?)$ & & & & \\
\hline Yawalapiti & & & & & & $x(?)$ \\
\hline
\end{tabular}

Fonte: elaborada pela autora, 2019.

Este tema ainda necessita de novos estudos, revisões, novas hipóteses e adições de outras línguas, para que, futuramente, possa ter um estudo mais consolidado desse sistema nas línguas Arawák. Dos cinco tipos analisados dos classificadores neste trabalho, o classificador de número é o tipo mais recorrente, o que colabora com hipótese de Grinevald (2000) de que os classificadores numerais são os mais predominantes nas línguas do mundo, os outros dois mais presentes são os verbais e de construções possessivas. Já os classificadores nominais, locativos e com adjetivos são os mais raros nessas línguas como podemos observar na tabela 3 acima.

É interessante verificar que embora essas línguas sejam geneticamente semelhantes, elas apresentam diferentes padrões tipológicos desse fenômeno. Desse modo, nota-se a importância de um estudo tipológico de línguas geneticamente relacionadas uma vez que, ao verificar tais padrões, podemos compreender as relações entre as semelhanças e também as diferenças tipológicas encontradas entre elas. 


\section{Considerações finais}

Segundo Grinevald (2000, p. 74), o objetivo da tipologia dos classificadores é duplo: por um lado, existe uma categoria linguística de "classificadores" em línguas do mundo que é distinta de outros sistemas de classificação nominal de natureza mais gramatical e, por outro lado, existem também vários tipos de classificadores que parece correlacionar com perfis semânticos diferentes. Para a autora, a função dos classificadores, em contraste com outros tipos de sistemas de classificação nominal, é de marcar uma individualização, uma característica inerente do nome.

Além desse processo individual, os classificadores desempenham um importante papel discursivo em muitas línguas (GRINEVALD, 2000). Isso pode ser visto nas línguas que foram selecionadas para análise sendo que os classificadores são propriedades apresentam valores funcionais e semânticos. Por exemplo, das 15 línguas analisadas, 11 apresentam classificadores em função anafórica: Ashéninka Perené, Baure, Baniwa de Içana, Mehináku, Nanti, Palikur, Paresi, Tariana, Wapixana, Warekena e Waujá. Desse modo, como postula Grinevald (2000, p. 76), "muitas descrições de sistemas de classificadores inclui uma menção e às vezes uma ampla ilustração desta função discursiva".

Em consonância com Aikhenvald (2000a), a tipologia de classificadores tornase necessária no sentido de estabelecer padrões abrangentes desse sistema em línguas do mundo. Portanto um estudo deste fenômeno pode auxiliar em novos dados e criar uma oportunidade de fornecer novos conhecimentos sobre esse sistema nas línguas do mundo. Muitas línguas estão perdendo o sistema de classificadores devido ao contato com outras línguas majoritárias. Assim sendo, é importante cada vez mais estabelecer estudos não apenas desse sistema, mas sim de outros fenômenos de categorização nominal como gênero, por exemplo, nas línguas, principalmente naquelas que estão em estado de obsolescência. 


\section{Referências}

ALLAN, K. Classifiers. Language, vol. 53, n. 2, 1977. p. 285-311. Disponível em: https://www.jstor.org/stable/413103?seq=1\#metadata info tab contents. Acesso: 22 out. 2018. DOI https://doi.org/10.1353/lan.1977.0043.

ALLIN, T. R. A Grammar of Resígaro. 1977. 551 f. Tese de Doutorado (Doctor of philosophy), University of St. Andrews., St. Andrews, 1976.

AIKHENVALD, A. Y. Classe nominal e gênero nas línguas Aruák. Boletim do Museu Paraense Emílio Goeldi, v. 10, 1994. p. 137-258.

AIKHENVALD, A. Y. Warekena. In: DERBYSHIRE, D. C.; PULLUM, G. K. (ed.). Handbook of Amazonian languages. Vol IV. Berlin/New York: Manton de Gruyter, 1998. p. 225-439.

AIKHENVALD, A. Y. The Arawak language family. In: DIXON, R. M.; AIKHENVALD, A. Y. The Amazonia languages. Cambridge: Cambridge University Press, 1999. p. 65-106.

AIKHENVALD, A. Y. Classifiers: a typology of noun categorization devices. Oxford linguistic, New York: Oxford, 2000a.

AIKHENVALD, A. Y. Unusual classifiers in tariana. In: SENFT, G. Systems of nominal classification. Cambridge: University Press, 2000b. p. 50-92.

AIKHENVALD, A. Y. Classifiers in multiple environments: Baniwa of Içana/Kurripako-a north Arawak perspective. International journal of American linguistics, n. 4, 2007. p. 474-500. DOI https://doi.org/10.1086/523774.

AIKHENVALD, A. Y. Language of the Amazon: a bird's - eye view. In: AIKHENVALD, A. Y. The languages of the Amazon. Oxford/New York: Oxford $\begin{array}{lllll}\text { University } \quad \text { Press, } & \text { 2012. } & \text { p. } & \text { DOI }\end{array}$ https://doi.org/10.1093/acprof:oso/9780199593569.003.0001.

AIKHENVALD, A. Y; GREEN, D. Palikur and typology of classifiers. Anthropological linguistics, vol. 40, n. 3, 1998. p. 429-480.

BRANDÃO, A. P. Classifier in Paresi-Haliti (Arawak). Moara, ed. 43, vol. 2, 2015. p. 51-67. DOI https://doi.org/10.18542/moara.v2i43.3838. 
BRANDÃO, A. P. A incorporação de nomes e classificadores em Paresi-Haliti (Arawák). Liames, Campinas, 2016. p. 271-283. DOI http://dx.doi.org/10.20396/liames.v16i2.8646341.

BRINTON, D. G. The American race: a linguistic classification and ethnographic description of the native tribes of North and South America. Studies in South American native languages. Philadelphia/New York: MacCalla \& Company, 1891.

CORBERA MORI, A. Aspectos da estrutura nominal em Mehináku (Arawák). Estudos linguísticos XXXVI, 2007. p. 250-257.

CORBERA MORI, A. Estruturas lexicais na língua Mehináku. In: FARGETTI, C. M. Abordagens sobre o léxico em línguas indígenas. Campinas: Curt, 2012, p. 127-143.

CORBETT, G. G. Gender. Cambridge: Cambridge University Press, 1991.

DANIELSEN, S. Baure: An Arawak language of Bolivia. In: Indigenous languages of Latin America. CNWS Publications, 2007. 500 p.

GILIJ, F. S. Saggio di storia americana, o sia, storia naturale, civile e sacra dei regni, e delle provincie spagnole di terra-ferma nell'America meridionale descritto dall'abate. Rome, 1783.

GRINEVALD, C. A morphosyntactic typology of classifiers. In: SENFT, G. Systems of nominal classification. Cambridge: University Press, 2000. p. 50- 92.

KAUFMAN, T. Language history in South America: what we know and how to know more. In: PAYNE, D. Amazonian linguistics: studies in lowland South American languages, University of Texas Press. Texas, 1990.

KIHN, A. What's in noun: noun classes, gender, and nouns. In: Laboratoire de Linguistique, 2014. p. 1-14.

LARSEN-HAURHOLM, S. A grammar of Garifuna. 2016. 325 f. Thesis (PhD.) Faculty of Humanities, Department of Linguistics, University of Bern, Switzerland, 2016.

MICHAEL, L. La incorporación nominal y los clasificadores verbales en Nanti (Kampa, Arawak). Proceedings of the second conference on the indigenous languages of Latin America. 2006. p. 1-27. 
MIHAS, E. Nominal classification in Asheninka Perene. Linguistic society of American, 2010. p. 1-5. DOI https://doi.org/10.3765/exabs.v0i0.510.

MIJUCA, M. I. Aspectos fonológicos e gramaticais da língua Yawalapiti (Arawák). 1992. 97 f. Dissertação (Mestrado em Estudos Linguísticos) - Instituto de Estudos da Linguagem, Universidade Estadual de Campinas, Campinas, 1992.

PAYNE, D. L. A classification of Maipuran (Arawakan) languages based on shared lexical retentions. In: DERBYSHIRE, D. C.; PULLUM, G. K. Handbook of Amazonian languages. Berlin/New York. Mouton - De Gruyter, v. 3, 1991. p. 355-499.

POSTIGO, A. V. Língua Wauja (Arawak): uma descrição fonológica e morfossintática. 2014. 244 f. Tese (Doutorado em Linguística) - Faculdade de Ciências e Letras, Universidade Estadual Paulista Júlio de Mesquita Filho, Araraquara, 2014.

SANTOS, M. G. dos. Uma gramática do Wapixana (Aruák): aspectos da fonologia, da morfologia e da sintaxe. 2006. 299 f. Tese (Doutorado em Estudos Linguísticos) Instituto de Estudos da Linguagem, Universidade Estadual de Campinas, 2006.

SENFT, G. What do we really know about nominal classification systems? In: SENFT, G. Systems of nominal classification. Cambridge: University Press, 2000. p. 50-92.

SOUZA, I. de. Koenukunoe emo'u: a língua dos índios Kinikinau. 2008. 299 f. Tese de Doutorado (Doutorado em Linguística) - Universidade Estadual de Campinas, Instituto de Estudos da Linguagem, Campinas, 2008.

SUAREZ, J. Classification of South American Indian languages. Encyclopaedia Britannica, 1974.

VON DEN STEINEN, K. Unter den Naturvölkern zentral-brasiliens: Reiseschilderung und Ergebnisse der zweiten Schingú-expedition (1887-1888). Berlin: Hoefer \& Vohsen, 1894.

WILSON, P. J.; LEVINSOHN. Una descripción preliminar de la gramática del Achagua. Bogotá: Instituto Lingüístico de Verano, 1992. 